\title{
MOBILE APP LEARNING LOUNGE
}

\author{
A SCALABLE AND SUSTAINABLE MODEL FOR \\ TWENTY-FIRST-CENTURY LEARNING
}

\author{
Michael H. Truong \\ Azusa Pacific Univeristy
}

Education in the mobile age does not replace formal education, any more than the worldwide web replaces the textbook; rather it offers a way to extend the support of learning outside the classroom, to the conversations and interactions of everyday life.

(Sharples, Taylor, \& Vavoula 2007, p. 243)

Twenty-first-century learning is increasingly defined by the use of mobile devices and applications. Centers for teaching and learning can help faculty and students acquire greater familiarity and fluency with just-in-time learning using mobile apps by creating informal, inviting, and informative learning spaces on their campuses. This chapter features the Mobile App Learning Lounge (MALL), a low-cost, highimpact initiative of a center for teaching and learning at a California research university. Beyond sharing how MALL works, this chapter offers practical suggestions and strategies for replicating a similar initiative at other institutions. 
In the 2012 Horizon Report, mobile applications (or mobile apps) ranked as the most immediate technology that has "impacts on virtually every aspect of informal life, and increasingly, every discipline in the university" (Johnson, Adams, \& Cummins, 2012, p. 6). Apps are the software that runs new mobile devices like smart phones and tablets, many of them equipped with always-on data network, cameras, accelerometer, and location-based technology. As of October 2012 there are close to 700,000 apps available for download within the Android marketplace and over 600,000 apps within the Apple marketplace. Moreover, smart phone and tablet users worldwide downloaded more than 45 billion apps in 2012, nearly twice as many as in 2011 (Reisinger, 2012).

Two key factors have facilitated the growth and popularity of mobile app use within the education sector. First is the plethora of the types of educational apps available. Given the thousands of educational apps, there is bound to be an "app for that" for whatever discipline, project, task, topic, or interest. There are many websites (e.g., appitic.com, iear.org, and teacherswithapps.com) dedicated to helping teachers and students find just the right app to accomplish a task. A second factor is the low cost of apps. Most educational apps cost a few dollars, and many ad-supported or limited-feature versions are free. Given the cheap price tag of most educational apps, students are more willing to pay for this kind of technology compared to purchasing software for their computers. The abundance and affordability of mobile apps have made it possible for students and teachers to customize their devices to suit their needs and interests easily and economically.

This chapter addresses two key questions: How is mobile technology affecting learning? and What role can centers for teaching and learning (CTLs) play in helping to foster the meaningful adoption of mobile technology at their campuses? I feature a nationally recognized initiative of the Center for Research on Teaching Excellence (CRTE Center) at the University of California, Merced (UCM): the Mobile App Learning Lounge (MALL). Beyond sharing how MALL supports undergraduate teaching and learning goals, this chapter offers practical tips and strategies for institutions interested in implementing (or enhancing already existing) mobile technology initiatives.

\section{Mobile Technology and Its Impact on Learning}

According to the EDUCAUSE Center for Applied Research's (ECAR) Study of Undergraduate Students and Information Technology Report (Dahlstrom, 2012), laptop ownership among college students nationally is currently around 85 percent (a change of 83 percent since 2004), and the rate of smart 
phone ownership is around 62 percent (a whopping change of 5,545 percent since 2004). Experts predict that the rate of smart phones and tablets ownership among students will continue to increase in the next couple of years to a point equal to or greater than that of laptops. Given their cheaper price tag, lighter form factor, and the ever-growing app market, mobile devices are poised to become students' primary and preferred technology for communication (e.g., SMS, e-mail, phone), social networking (Facebook, Twitter), and course management (accessing course materials, checking grades, completing assessments) (Johnson, Adams, \& Cummins, 2012).

Mobile learning has not just changed but dramatically challenged the traditional academic context (Brown \& Diaz, 2010). For example, the high rate of ownership of smart phones and other mobile devices like laptops has made keeping mobile technology out of the classroom almost impossible. Course policies could mitigate the presence of cell phones, but perhaps a more fruitful approach to this technology would be to leverage them toward academic and classroom purposes, bridging the social and the academic worlds students straddle. As a result, teachers must learn how to channel and direct mobile technology use among their students to support the curriculum constructively. Otherwise the enormous potential of mobile technology to improve learning will go unrealized or, worse, disconnected from the daily realities of students.

\section{Redefining the Classroom}

Mobile learning is not just challenging the traditional understanding of the classroom as the center of learning; it is also demystifying the way students learn (Sharples, Arnedillo-Sanchez, Milrad, \& Vavoula, 2009). In the traditional classroom model, an illusion of centrality is supported by a fixed location, common resources, a single teacher, and a facultyderived curriculum. In reality, learning (both formal and informal) has never been bounded by any particular location, time, topic, or technology. Rather, it occurs between and across these contexts, whereby what is learned in one domain influences and is informed by another. For example, much of what students learn in informal contexts (from friends and the media, say) can become a resource for more formal contexts like seminars, lecture halls, and exams. With the advent of always-on mobile devices, students can navigate between and across these contexts more easily, more quickly, and more seamlessly, learning to make meaning from the flow of everyday activities.

Students with mobile devices and constant communication do not fit the traditional educational model (Sharples et al., 2007). Traditional classroom learning is regulated by curriculum and mediated by a teacher, 
which contrasts significantly from the rich interaction of mobile learning with texts, Twitter, and Tumblr. Higher education is entering what Randy Bass (2012) refers to as the "postcourse era"-a time when the formal curriculum of bounded, self-contained courses is no longer the primary place where the most significant learning takes place. Mobile technology is unbundling the course and paving the way for ubiquitous learning, defined as true, authentic learning that takes place beyond the classroom walls, without a formal curriculum, and absent formal teacher figures (Cope \& Kalantzis, 2009).

Mobile technology is ushering in what is being called just-in-time or ondemand learning-the concept that students with network-connected mobile devices can access relevant information in the immediate context they are in and at the exact time they need it. For example, in a class where all course materials (syllabus, readings, assignments, lectures, and so on) are available on a learning management system (LMS), students are able to access what they need, wherever they are, and whenever they need it. This learning model radically transforms the traditional learning environment, characterized as static, inefficient, and standardized, into a dynamic, interactive, and customized environment where students become active agents in their own learning (Hall, 2001). In this new environment, students, performing at varying levels with varying types of needs, in theory can get the appropriate information they seek at just the right time.

In short, instead of seeing mobile learning as a threat to formal education, teachers can identify and harness the potential benefits of mobile technology to transform the learning experience for their students. Here are four concrete examples of how mobile learning can radically redefine the classroom.

- Interspersed learning. Since mobile devices tend to be highly personal and portable, like a wallet, individuals typically take their devices wherever they go. As a result, learners can fit learning into their own schedule (as opposed to rigid, scheduled times), enabling them to learn during down time and in transit. For example, students using digital text/book apps like Kindle, Kno, Inkling, and CourseSmart can access their course readings at their convenience throughout the day with just one device compared to having to carry all of their course texts.

- Social learning. Mobile devices allow teachers and students to have greater access to and communication with one another, making mobile learning inherently more interactive and social. For example, text messaging and other messaging apps like Facebook Messenger, 
Voxer, Skype, and Twitter facilitate direct and instantaneous communication between two individuals or a group of individuals. Teachers and students can send reminders and time-sensitive messages, providing just-in-time and just-enough information. (One caveat is the importance of setting boundaries, protecting intrusions into private lives. For example, teachers and students alike probably do not appreciate receiving text messages at midnight or other odd times. It is important to have policies establishing ground rules of using this form of communication.)

o Context-based learning. Most mobile devices equipped with GPS and other context-awareness features bring a new dimension to learning in the field. For example, students doing fieldwork or on a field trip can use apps like Evernote and Catch to take pictures, write notes, and record audio and video files-all of which will have contextual data, such as the exact time, location, and condition of when and where the data were collected.

o Reflective learning. Mobile devices can be used to record personal reflections and engagement with materials as learning happens. For example, students can use annotation apps like Adobe Reader, Notability, and iAnnotatePDF to highlight and mark up what they are reading. Moreover, study apps like StudyBlue and Quizlet allow students to create flash cards based on reading materials that they can use for reviewing and reinforcing key concepts and understanding.

\section{Improving Student Learning and Engagement}

One of the key questions surrounding the efficacy of mobile learning in higher education is whether it improves learning. According to one of the earliest empirical studies, students' use of a mobile app in an introductory statistics class increased their motivation and improved their ability to obtain significantly higher final grades (Nihalani \& Mayrath, 2010). The researchers cited the portability and interactive tools of the apps as the primary motivations for continued use, leading to improved student learning experiences. Moreover, students reported using the mobile app more often than they used their textbooks. Other studies involving the use of iPads have yielded similar positive results, including improved performance on course learning outcomes (Hoover \& Valencia, 2011), increased content engagement (Marmarelli \& Ringle, 2011), and enhanced academic experience (Walker, 2011). Mobile devices coupled with appropriate educational apps have increased students' engagement 
and interaction with course content, augmented face-to-face instruction, and ultimately led to improved performance.

According to Belshaw (2011) of JISC InfoNet, United Kingdom's leading advisory organization on information and learning technology for higher education, mobile learning works because it not only aligns well with many goals of educational institutions (e.g., curriculum redesign, digital literacies, reducing costs) but also reinforces established principles of learning (e.g., personalized learning, active learning, increased engagement). A case in point is our library's iPod Touch Tour-a virtual tour downloaded on an Apple iPod Touch designed to help students get acquainted with the library's services, space, and resources (Davidson \& Mikkelson, 2009). After the virtual tour, students complete an assignment that assesses their understanding of the library's space, services, and resources. Based on two years' worth of data, the library found that students who did the iPod Touch Tour scored just as well as, if not better than, in-person instruction. Moreover, students noted a significant preference for learning about the library using the iPod Touch Tour compared to other synchronous in-person methods.

The power of mobile learning is being leveraged across many areas of higher education. Many institutions already use modern LMSs, such as Blackboard, Desire2Learn, and Canvas, that come with mobile access via native or web apps, allowing students to access their course resources, complete surveys, submit assignments, and communicate with instructors and peers. Moreover, many discipline-specific apps are helping students develop and deepen disciplinary knowledge in ways that learning with desktop and laptop computers cannot or is not as convenient. For example, in mathematics, apps such as Wolfram Alpha Course Assistant, Video Calculus, and Khan Academy help students learn and reinforce key mathematical concepts using audio and video files, question banks, and step-by-step problem-solving tutorials. For students majoring in life sciences, Biology Buddy, The Elements, and Science360, among other apps, are designed to inform, instruct, and inspire users to hone their skills in the discipline. Beyond anywhere, anytime availability, many educational apps leverage the audio, video, spatial, and interactive interfaces mobile devices afford, making learning deeper, richer, and longer compared to traditional approaches.

\section{The Role of CTLs in Fostering Mobile Learning}

Mobile learning is not merely changing higher education; it is transforming it in profound ways. "Faculty benefit [from mobile learning] 
because students are more engaged. They [students] are more interested in the material, they operate at a more advanced level, and it has actually been the most rewarding teaching I've done in 25 years," says Bill Rankin, director of educational innovation at Abilene Christian University (2012). Mobile learning promises to help teachers and learners communicate more frequently, collaborate more closely, and converge around learning. In other words, CTLs can leverage mobile learning to enhance curriculum, reimagine pedagogy, and ultimately transform roles whereby students are seen as participants and agents in learning activities and teachers act as their guides and mentors. Moreover, the "classroom" is no longer defined by or confined to the physical space within four walls, but exists also in virtual space, including e-mails, discussion forums, chat, social media sites, and many other channels. The key question for CTLs is figuring out how to harness current and emerging trends in mobile learning into practical pedagogies and best practices that are helpful to advance teaching and learning.

Many universities have robust mobile learning initiatives. Arguably, the best publicized is Abilene Christian University's (ACU) Connected Initiative. Since 2007, ACU has been providing its four thousand students and seven hundred professors with iPhones and, more recently, with iPads, making them a one-to-one device campus. ACU's innovative mobile learning initiative has helped garner it national and international attention, making it a model school for how mobile learning can enhance and extend learning inside and outside the classroom. Similar initiatives at other universities, including MIT, Boise State University, and Northeastern University, have received less publicity, but they too have done innovative work to show how mobile learning is helping to improve student learning and engagement.

These mobile learning initiatives are hard to duplicate at other campuses because they require extensive resources in terms of funding, personnel, and expertise. As a result, schools that are resource strapped (and many are these days) may feel they are not able to embark on similar initiatives. Another issue is that most campuses are typically bigger and fiscally more challenged than ACU and other private institutions with campuswide mobile initiatives. To address these implementation challenges, our center has taken mobile learning to a social format, bridging the gap between traditional classrooms and learning in the twentyfirst-century. The MALL project offers an alternative low-cost, highimpact model that requires significantly fewer resources and yields equally important results. 


\section{Conceiving MALL}

It is not uncommon to find students listening to their music on their portable device or tapping away at their phones or tablets on most college campuses. In fact, on my daily bus commute to campus, I see the majority of the riders, most of them students, with their eyes glued to their mobile device screens (as I am too). This scene is not restricted to the bus. As I get off the bus at the campus library stop and walk to my office building, I see most students carrying a mobile device in one hand and their backpacks or books in the other. Since owning a mobile device became affordable and mainstream, many students have found themselves increasingly reliant on their devices in the same way they have with their desktop and laptop computers to get them through the day. CTLs have an important role to play in helping campus communities use mobile technology appropriately and effectively. For example, mobile technology is ideal for certain kinds of learning experience (e.g., creating flash cards, reviewing recorded lectures, looking up facts and information) and not for others (composing their essays on their tablets, fostering teamwork). In short, CTLs can educate a campus about innovative and appropriate ways to leverage mobile technology without compromising the learning experience.

In summer 2010, the center acquired access to forty Apple firstgeneration iPads, purchased by the writing program through a federal grant. Our center partnered with the writing program to create a loaner system that allowed faculty to check out iPads on a short-term basis as a way to explore their potential uses. Starting in spring 2011, the center made these iPads available for small seminar classroom use, whereby a faculty member can check out up to twenty iPads for use during a class session. Initially faculty employing these iPads mostly used them like laptops, asking students to look things up on the Internet. As the Apple iTunes Apps Store matured and offered more educational apps, faculty employed iPads in more sophisticated ways, such as using mind-mapping (MindMeister) and note-taking apps (Evernote) to facilitate brainstorming and writing sessions.

In fall 2010, the center explored ways to extend and expand the use of the forty iPads by approaching the library and asking it to host a monthly event open to the entire campus. The librarians offered one of their instructional rooms that was equipped with an LCD projector and a smart board. Because we wanted to create an environment that was physically comfortable and technologically engaging, the room was not set up like a typical classroom with tables and chairs forward facing. 
The CRTE and the library brought in comfortable couches and set up tables and chairs to encourage and foster collaboration. It is important to note that the room where MALL takes place did not compromise the library's instructional spaces. Because it is a heavily used room, the layout had to stay multifunctional with flexible furniture. Prior to each MALL event, the library would set up the room and revert the room back to a classroom setup after the event. In the end, we created a learning loungea fun, social, and educational playground for participants to gather, share, and learn from one another. With a learning lounge in place, the first MALL event took place in January 2012.

The key lesson for CTLs interested in starting a similar mobile initiative is to identify an ally, partner together, and collaboratively bring the initiative to life. Through sharing their mobile devices, the writing program served as the initial impetus. Instead of purchasing devices, CTLs can partner with academic units that have already purchased or plan to purchase devices for their mobile initiative. Moreover, the library has been an ideal partner because it has premium real estate on campus-one that is frequently occupied by students and faculty and conveniently located at the heart of the campus. Having events located in the library made it easier to attract participants because it was already a high-traffic, high-profile location. Moreover, the mission of the library, focused squarely on information literacy and technological fluency, aligned and reinforced the goals and outcomes of the MALL initiative. Besides the library, other potential allies exist in academic affairs (e.g., the Learning Center, the Office of Undergraduate Studies) and student affairs (the Office of Student Life, Residential Life). The strategy is to find an ally open to experimenting with learning spaces and leveraging mobile technology to advance teaching and learning.

\section{Learning Lounge Layout}

The design of physical spaces has an impact on learning in profound ways. Researchers have noted that learning spaces are themselves agents of change, and changed spaces can produce a change in pedagogy and practice (Joint Information Systems Committee, 2006). In other words, there is a built-in pedagogy in most learning spaces, whether that is the traditional classroom or informal study halls (Oblinger, 2006). Many students today prefer to learn in active, participatory, experiential ways, as opposed to sitting and listening to their professors. To that end, welldesigned learning spaces can encourage exploration, collaboration, and inspiration. 
MALL is designed to be experience-centric and focused on the learner, as opposed to presentation-centric, which typically foregrounds the teacher. The learning lounge allows participants to come and freely explore at their own pace and based on their interests. Individuals who do not have their own device can check out a loaner iPad, loaded with featured educational apps. A few volunteer facilitators are always available, roaming the room, ready and willing to engage with participants. The environment is similar to what one would find at an Apple Store, a museum, or an art gallery.

MALL offers bite-sized resources that can be consumed quickly and easily. Instead of a formal lecture or presentation about the latest and greatest mobile apps, participants get many small tips and ideas that are easy to digest and quick to implement for a wide range of participants from instructional staff, to undergraduates, to faculty. At every event, we distribute a one-page handout filled with featured apps and their practical application. Many participants who do not have time to stay the entire session simply stop by and grab a handout (also available on our website). What participants learn at MALL is meant to whet their appetite, not make them full. The intention is similar to Ted Talks, movie trailers, and appetizers before the main course.

In addition to being experience-centric and bite-sized, MALL promotes group learning. Learning today happens in community and distributed networks (Siemens, 2005; Thomas \& Brown, 2011). Instead of one expert and many learners, MALL events encourage all participants to connect, share, discuss, engage, and learn with and from one another. The expertise and content are crowd-sourced and come directly from the participants, not any one particular person. The creation of meaning and the spark of learning happen in the act of exchange among participants. It is the same principle employed by Wikipedia, discussion forums, and social network sites. Participants who are new to mobile technology observe others, ask questions, and experience firsthand how mobile apps might benefit them. Experienced participants get to showcase their favorite apps, talk about how they use them, and share personal tips, tweaks, and frustrations. Our center also employs and trains student assistants to serve as teacher models for their peers during the event.

To facilitate learning that is centered on experience, bite-sized content, and group learning, the room is divided into two primary spaces. The first is a show-and-tell area located around the LCD screen, where volunteer presenters give brief presentations (less than five minutes) about their favorite apps and how they use them to accomplish common tasks (e.g., annotating readings, taking notes, managing files). The majority of 
the presentations are typically done by students. Faculty and staff who attend MALL are interested in learning how to leverage mobile technology to better reach and engage their students. The rest of the lounge is a free exploration area where participants congregate around the couches and tables, asking questions, sharing tips, and troubleshooting problems. In short, MALL serves as a rich learning community, bringing together learners of all types around mobile technology. Often interactions that begin at MALL continue beyond the event through sharing contact information or connecting to each other's social network Facebook or Twitter accounts.

In addition to developing instructors, CTLs need to play a greater role in the design of learning spaces on college campuses. Through designing new spaces or reimagining existing ones, CTLs can foster twenty-firstcentury learning, characterized by mobility, flexibility, and interactivity. At our campus, we were able to change the built-in pedagogy of the library by converting a traditional classroom into a learning lounge for MALL events. We have created a new learning space that encourages participants to explore mobile learning and, we hope, inspires new pedagogy and practices.

\section{Scaling and Sustaining the Initiative}

Designated as a Hispanic-serving institution (HSI), the University of California, Merced, enrolls six thousand students, with projected growth to ten thousand students by 2020 . The diverse student demographic at our institution is distinctive, with a majority of our students of Hispanic background, Pell Grant recipients (low-income), and firstgeneration college goers. This population is particularly at risk not to finish a college degree.

MALL events serve as a small yet important intervention, providing our students opportunities to learn, experience, and develop fluency around mobile technology. The events help reinforce high-impact educational practices such as fostering faculty-student interactions, learning communities, collaborative learning, and experiential learning-practices that have been proven to improve student retention and persistence among students in general and minority students in particular (Kuh, 2008). MALL events also attempt to close the ever-widening digital divide that many of our at-risk students face. Mobile technology has become such an integral part of learning that a student without access to a mobile device is regarded as disadvantaged. While the ownership rate of mobile devices among college students is around 60 percent nationally, 
the rate at our campus is half that, around 30 percent, according to a recent campus IT survey. Through MALL events and our iPad loaner program, students have access to these devices. Our financial aid office has worked closely with students and their families to ensure they can afford to purchase the appropriate technology necessary to succeed during their tenure as students.

Given the popularity and success of MALL events, the CRTE and the library are well positioned to expand the initiative. However, like most other public universities in recent years, our institution is facing severe budget cuts and constraints, so scaling our mobile learning initiative must be done in a way that is strategic and sustainable. In particular, we have developed five principles that will guide the continued development and growth of our mobile learning initiative.

First and foremost, we will need to work with IT to ensure that the wireless network throughout the campus will be robust enough to support the proliferation of devices. Our campus wireless networks are aging and reaching their limits, especially in high-density areas like the library and the classroom buildings. For mobile learning to become more widespread at our campus, IT will need to bolster the wireless infrastructure, as well as prepare to support hardware problems, such as device malfunction and troubleshooting.

Second, we will continue to align MALL to contribute directly to campus mission and priorities: student success, teaching effectiveness, and technological stewardship. We have been collecting participant feedback from each MALL event, and it has provided us valuable insight into the initiative's effectiveness and impact. We plan to extend our assessment strategy by doing a campuswide survey regarding the use of mobile technology to improve teaching and learning. When a mobile learning initiative addresses campus concerns head-on and is supported by data, it invites attention, allies, and, we hope, administrative support and resources from the top.

Third, the MALL initiative will need to focus on added pedagogical and practical value for our campus community. In other words, stakeholders, especially teachers and students, need to see tangible benefits when employing mobile technology. For students, it might mean seeing their grades improved because of the use of a specific app. For faculty, it might mean reducing their workload because a particular app helps them do something more quickly or more easily. In short, the addition of technology alone is not enough; it must be deployed purposefully and meaningfully to achieve results. Participants take what they learn at 
MALL and apply it to their respective contexts, with the goal of improved experiences, learning, and productivity.

Fourth, MALL will need to continue as a low-cost, high-impact initiative in order to be scalable in tough economic times. Currently one paid staff and two student assistants spend about five hours planning, publicizing, and organizing each MALL event. MALL will continue to rely on the many participants who volunteer at each event, giving presentations, facilitating discussion, and providing content. This is a crowd-sourced model for sustaining our mobile learning initiative.

Finally, to establish MALL and put it on a sustainable path, we need to strengthen our partnership with the library, while also inviting other campus units to join in. We hope to partner with the academic schools, the bookstore, and other units, striving for mutual benefits. The collective approach could lead to the pooling of resources to expand MALL and its impact on campus.

\section{An Invitation to Exploration and Inspiration}

The potential benefit of mobile technology on teaching and learning is incalculable, and CTLs should not leave the important task of forging a mobile learning strategy on their respective campuses to others. Those most concerned about teaching and learning should work to realize some of the promises of anytime, anywhere learning by using mobile devices and apps. At the same time, we should also work to resolve some of the known barriers and bottlenecks, such as the lack of awareness and fluency with how to apply this technology appropriately and meaningfully to improve student learning.

Like most other disruptive innovations, mobile devices and their impact on learning will not be fully understood or valued until they become common practice. Rather than waiting for the dust to settle, campuses waiting on the sidelines should begin to take small steps and get involved immediately, perhaps by starting an initiative like MALL. CTLs should consider MALL as a first step-one that serves as a springboard to more ambitious projects, such as organizing small pilots or awarding mini-grants for faculty to experiment with mobile devices in their classrooms. The sooner a campus establishes a culture for mobile learning, the sooner it will be able to identify best practices and address some of the barriers and roadblocks. For campuses not engaged with mobile learning, MALL represents an invitation to come, explore, and be inspired. 


\section{REFERENCES}

Abilene Christian University. (2012, September 7). Rankin, mobile learning initiative featured on Icelandic television. ACU News. Retrieved from http://www.acu.edu/news/2012/120907-rankin-mobile-learning-featured-on -icelandic-tv.html

Bass, R. (2012). Disrupting ourselves: The problem of learning in higher education. EDUCAUSE Review, 47(2). Retrieved from http://www.educause.edu /ero/article/disrupting-ourselves-problem-learning-higher-education

Belshaw, D. (2011, August 31). Why mobile learning. Retrieved from https:// mobilelearninginfokit.pbworks.com/w/page/41751178/Why-mobile-learning

Brown, M., \& Diaz, V. (2010). Mobile learning: Context and prospects. Retrieved from http://net.educause.edu/ir/library/pdf/ELI3022.pdf

Cope, B., \& Kalantzis, M. (Eds.). (2009). Ubiquitous learning. Champaign: University of Illinois Press.

Dahlstrom, E. (2012). ECAR study of undergraduate students and information technology, 2012 (Research Report). Retrieved from http://net.educause .edu/ir/library/pdf/ERS1208/ERS1208.pdf

Davidson, S., \& Mikkelsen, S. (2009). Desk bound no more: Reference services at a new research university library. Reference Librarian, 50(4), 346-355. doi: $10.1080 / 02763870903143591$

Hall, L. (2001). Just-in-time learning: Web-based/Internet delivered instruction. In Proceedings of the Seventh Americas Conferences on Information Systems 2001 (pp. 912-914). Boston, MA. Retrieved from http://frank.itlab.us /forgetting/just_in_time.pdf

Hoover, D., \& Valencia, J. (2011). iPads in the classroom: Use, learning outcomes, and the future. Paper presented at the EDUCAUSE Annual Conference. Retrieved from http:/www.educause.edu/sites/default/files/library /presentations/E11/SESS081/iPads +in +the+Classroom.pdf

Joint Information Systems Committee. (2006). Designing space for effective learning: A guide to 21st century learning space design. Retrieved from http://www.jisc.ac.uk/uploaded_documents/JISClearningspaces.pdf

Johnson, L., Adams, S., \& Cummins, M. (2012). The NMC Horizon Report: 2012 higher education edition. Retrieved from http://www.nmc.org/pdf 12012-horizon-report-HE.pdf

Kuh, G. D. (2008). High-impact educational practices: What they are, who has access to them, and why they matter. Washington, DC: Association of American Colleges and Universities. Retrieved from http://www.neasc.org /downloads/aacu_high_impact_2008_final.pdf

Marmarelii, T., \& Ringle, M. (2011). The Reed College iPad study. Retrieved from http://www.reed.edu/cis/about/ipad_pilot/Reed_ipad_report.pdf 
Nihalani, P., \& Mayrath, M. (2010). Mobile learning: Evidence of increased learning and motivation from using an iPhone app. Retrieved from hatp:// gylo.com/WhitePaper_03302010_Stats1.pdf

Oblinger, D. G. (2006). Space as a change agent. In D. G. Oblinger (Ed.), Learning spaces (pp. 1.1-1.4). Louisville, CO: EDUCAUSE. Retrieved from htrp://www.educause.edu/research-and-publications/books/learning-spaces

Reisinger, D. (2012, September 27). Can Apple's Apple's App Store maintain its lead over Google Play? Retrieved from http://news.cnet.com 18301-1035_3-57521252-94/can-apples-app-store-maintain-its-lead-over -google-play 1

Sharples, M., Arnedillo-Sanchez, I., Milrad, M., \& Vavoula, G. (2009). Mobile learning: Small devices, big issues. In N. Balacheff, S. Ludvigsen, T. de Jong, A. Lazonder, \& S. Barnes (Eds.), Technology-enhanced learning (pp. 233-249). Dordrecht, Netherlands: Springer. doi:10.1007/978-14020-9827-7

Sharples, M., Taylor, J., \& Vavoula, G. (2007). A theory of learning in the mobile age. In R. Andrews \& C. Haythornthwaite (Eds.), The Sage handbook of elearning research (pp. 221-247). London, UK: Sage. doi:10.4135 19781848607859

Siemens, G. (2005). Connectivism-a learning theory for the digital age. International Journal of Instructional Technology and Distance Learning, 2(1), 3-10. Retrieved from hrtp://itdl.org/journal/jan_05/article01.htm

Thomas, D., \& Brown, J. S. (2011). A new culture of learning: Cultivating the imagination for a world of constant change. Lexington, KY: CreateSpace.

Walker, J. D. (2011). The student experience: Student survey and focus group preliminary. Retrieved from http:/www.oit.umn.edu/prod/groups/oit/@pub /@oit@web/@evaluationresearch/documents/article/oit_article_354354.pdf 